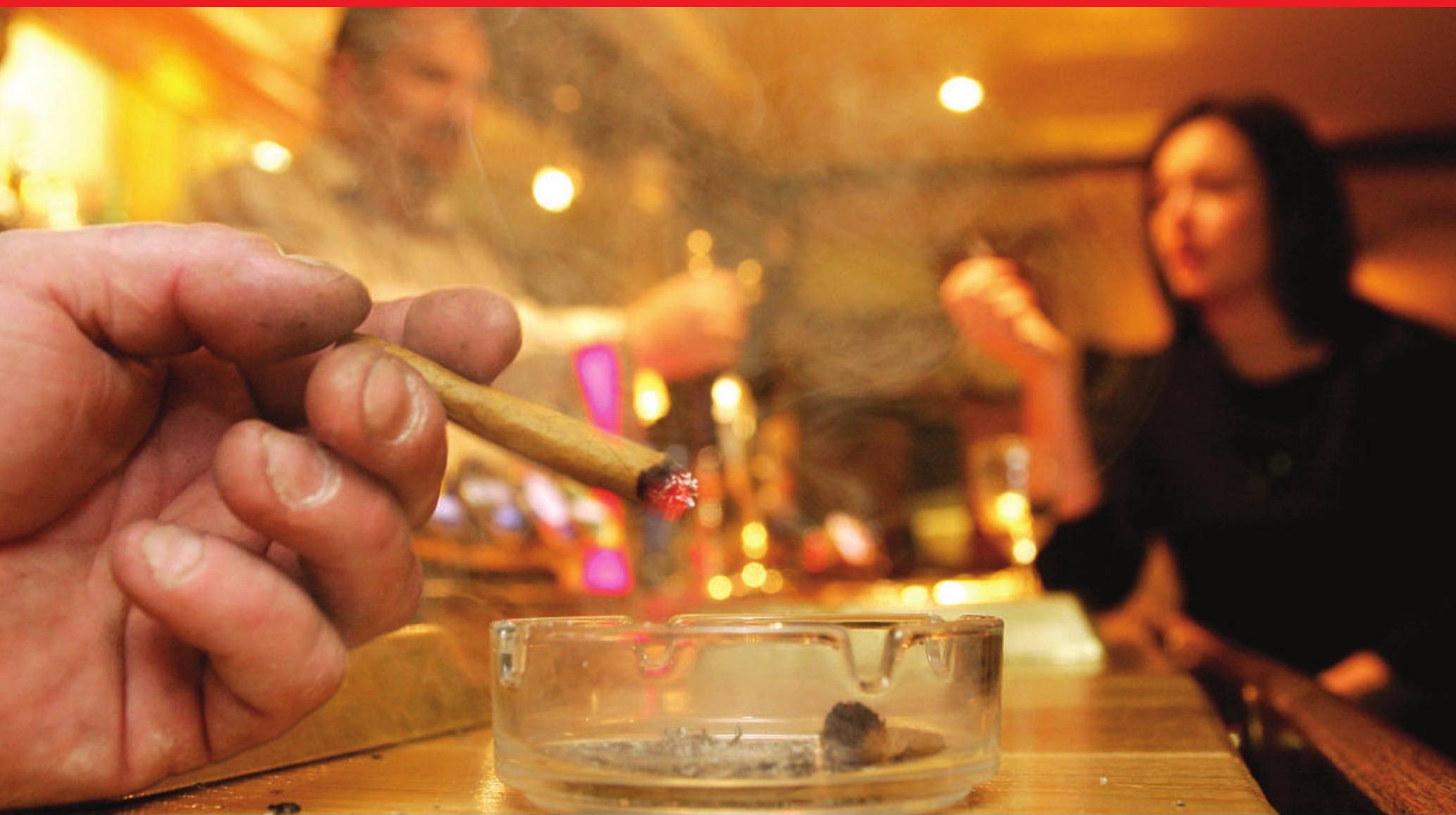

\title{
Out from the haze
}

\section{Smoking was banned in Californian bars a decade ago, and this week England follows suit. But Kris Novak finds that epidemiologists are still arguing about the effects of second-hand smoke.}

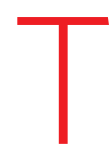

he reactions to the English ban on smoking in all enclosed public places on 1 July are almost as predictable as a chain smoker's second pack of the day. "First you'll read that all the pubs are going broke, then that people are blocking the street when they stand outside smoking, creating traffic congestion, and then everyone will be told that the ban is wildly unpopular," says Stanton Glantz, director of the Center for Tobacco Control Research and Education at the University of California, San Francisco. "It happens every time these bans go into effect. After the wave of bad press, everything will calm down and next year everyone will say, 'What was the big deal?'”

Glantz should know - he was involved in the first widespread ban on smoking in workplaces, including bars and restaurants, which has been in effect in California for almost ten years. Lately, he has advised public-health officials from around the world on how to enact similar legislation.

Back in 1998, banning smoking in bars was not easy, even in clean-living California. The ban met with resistance from groups claiming that making bars smoke-free would devastate businesses, deny adults the freedom to smoke and be too difficult to enforce. The tobacco industry made nine attempts to repeal the law and spent US\$18 million on a public-relations campaign against it.

However, a smaller but well-organized public-health campaign overcame resistance to the ban. Glantz says that it's important that governments explain the dangers of second-hand smoke to non-smokers. In his view, passive smoking has been the Achilles' heel of tobacco companies, taking the focus off the rights of smokers and placing it on the health of nonsmokers. True to this script, over the past six months, the UK government's health department has spent $£ 8.7$ million (US $\$ 17.3$ million) on an advertising campaign to educate English citizens about second-hand smoke and prepare businesses for the change.

\section{Coronary concerns}

Despite all the strongly worded advertising campaigns, the health benefits of smoking bans for non-smokers have been controversial. One of the biggest rows concerns the links between second-hand smoke and heart disease - an argument in which Glantz has been a key player. Richard Peto at the University of Oxford, who has been studying tobacco use for more than 30 years, says: "Passive smoking must kill some people, but the big question is how many."
Smoking has been banned in all workplaces, including bars and restaurants, in more than 20 countries (see table) and in many US states. In $\frac{O}{n}$ March 2004, Ireland became the first country to enact such a ban. "Ireland is a huge success 4 story," says Glantz, paving the way for bans in Scotland, Wales, Northern Ireland and now England, the largest nation to do so. Glantz cited the active support of Ireland's health minister and television campaigns that warned people of the dangers of second-hand smoke.

Because California has the longest history of smoking restrictions, epidemiologists often turn to the state's public-health data to determine the effects of smoking bans, on both smokers and non-smokers. Back in 1988, California voters approved the California Tobacco Control Program (CTCP), which increased tax on cigarettes to fund tobacco education programmes, and went on to ban smoking in workplaces (including restaurants) in 1995 and in bars in 1998 .

Several studies show that the CTCP helped Californian smokers to quit. In 1988, 23\% of all Californians smoked and by 2006 that number had dropped to $13 \%{ }^{1}$. Similar effects have been seen in Europe: in Scotland, cigarette sales fell by $8 \%$ in the first year of its ban, and Ireland has seen about a $5 \%$ drop in the number of 
$₫$ smokers since the 2004 ban, although $25 \%$ of Irish people still smoke. or without a ban? Peto notes that smokingrelated deaths in the United Kingdom have already declined by almost $50 \%$ since the late1960s. "Smoking bans will probably affect some additional people," he says, but separating that effect from the overall decline in smoking is a complex task.

The California experience suggests that legislation has a role. More than half of California's former smokers agreed that the smoke-free workplace and bar laws made it easier for them to quit, and most smokers reduced their cigarette consumption because of the bans ${ }^{1}$. According to the European Commission, the United Kingdom has the highest percentage of European smokers who are trying to quit (46\%), so the 1 July ban could be a step in the right direction.

\section{Tips for non-smokers}

If smokers are giving up in droves, is their health also improving after the bans? Once again, the California experience is helpful with those for US states without smoking bans. Between 1988 and 2002, rates of lung and bronchial cancer declined four times faster in California than in the rest of the United States ${ }^{1}$.

Peto, however, is sceptical of studies that associate mortality trends in large populations with a single event. "The number of deaths from vascular disease and cancer have been falling for multiple reasons, such as improved treatments; at the same time, you have increases in disease rates because of obesity - there are just too many things going on to attribute changes in mortality to one single thing," says Peto. He thinks that it takes decades for population-wide changes in health trends to become apparent.

But what about the health benefits of smoking bans for non-smokers? These are even more uncertain. Banning smoking does clean up the air in bars - an Italian study comparing air quality before and after their 2005 ban found a $95 \%$ reduction in airborne nicotine $e^{2}$. Within $\Sigma$ months of bans on smoking in bars in Ire-
But were these changes on their way, with because public-health data can be compared

\begin{tabular}{|l|l|}
\hline Country & Year of smoking ban \\
\hline Argentina & Regional bans in 2006 and 2007 \\
\hline Australia & Regional bans in 2006 and 2007 \\
\hline Bhutan & February 2005 \\
\hline Denmark & April 2007 \\
\hline England & July 2007 \\
\hline Finland & June 2007 \\
\hline France & Scheduled for January 2008 \\
\hline Hong Kong & January 2007 \\
\hline Hungary & Scheduled for 2009 \\
\hline Iceland & June 2007 \\
\hline Ireland & March 2004 \\
\hline Italy & January 2005 \\
\hline Lithuania & January 2007 \\
\hline Netherlands & Scheduled for July 2008 \\
\hline New Zealand & December 2004 \\
\hline Northern Ireland & April 2007 \\
\hline Norway & June 2004 \\
\hline Portugal & May 2007 \\
\hline Scotland & March 2006 \\
\hline Sweden & June 2005 \\
\hline Thailand & August 2007 \\
\hline Wales & April 2007 \\
\hline Uruguay & March 2006 \\
\hline
\end{tabular}

land and Scotland, bar workers reported fewer respiratory problems, and breath, saliva and blood samples contained fewer biomarkers of tobacco exposure than before the bans ${ }^{3,4}$.

According to Smokefree England, an educational website funded by the UK health department, second-hand smoke contains more than 4,000 different chemicals, such as carbon monoxide, and more than 50 carcinogens, including chromium, vinyl chloride and benzene. So does cleaner air prevent disease in non-smokers?

Smokefree England claims that exposure to second-hand smoke increases a non-smoker's risk of getting lung cancer by $24 \%$ and

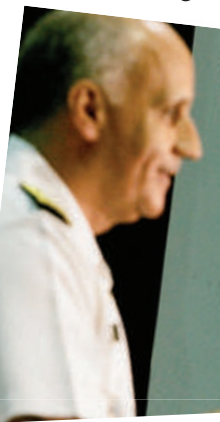
risk of heart

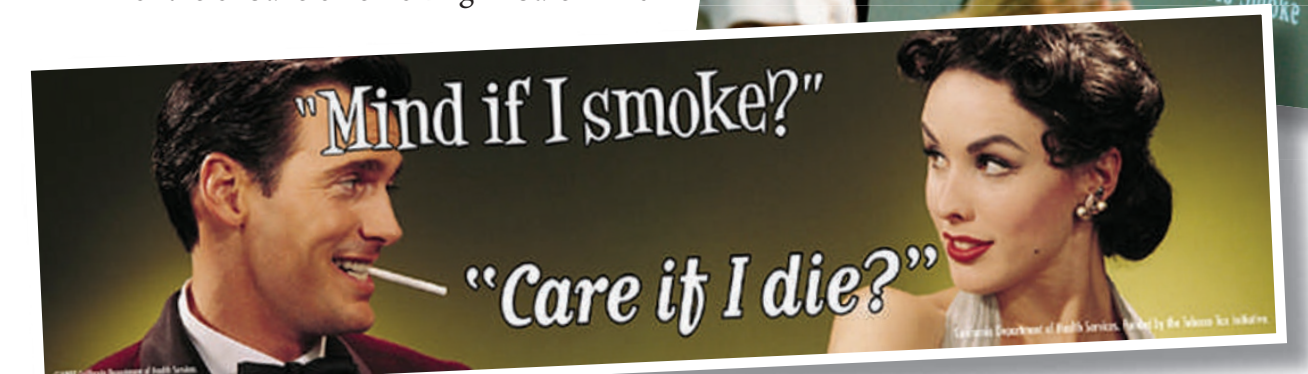

Campaigns against passive smoking often cite data from the 2006 US surgeon general's report (top). disease by $25 \%$. But where do these numbers come from? "These are generally accepted numbers," says epidemiologist Alfredo Morabia, at Queens College in New York, who cites the 2006 US surgeon general's report, The Health Consequences of Involuntary Exposure to Tobacco Smoke, the US government's most detailed statement ever on second-hand smoke ${ }^{5}$.

For lung cancer, there is general agreement with the report's assessment. Studies of nonsmokers who live with a smoker suggest that the risk of developing lung cancer is about 25 times higher in smokers than non-smokers. Because non-smokers' exposure to secondhand smoke is estimated to be about $1 \%$ that of a smoker, a $24 \%$ increase in lung-cancer risk (0.24-fold) fits with expectations.

\section{Cardiac effects}

But the data supporting the link between second-hand smoke and cardiovascular disease are more controversial. The surgeon general's report states that "pooled relative risks from meta-analysis indicate a $25-30 \%$ increase in risk of coronary heart disease from exposure to second-hand smoke". Although most epidemiologists think there is a link, it's the size of the effect that surprises them.

"It seems to me that a $25 \%$ increase is not plausible," says John Bailar, a biostatistician at the National Academy of Sciences in Washington DC, who thinks the effect should be proportional to exposure, as it is for lung cancer. "Regular smoking only increases the risk of cardiovascular disease by $75 \%$, so how could second-hand smoke, which is much more dilute, have an effect one-third that size"? Bailar says that even if a non-smoker took in $10 \%$ as much smoke as a smoker, which is

a high-end estimate, his increased risk would be only $7.5 \%$.

One explanation offered by Glantz and other heart researchers for the higher-than-expected effect of second-hand smoke on coronary heart disease is that the 'sidestream' smoke a non-smoker breathes is more toxic, per gram of total particulate matter, than the 'mainstream cigarette smoke' that a smoker inhales ${ }^{6}$. So small amounts of sidestream smoke might be more likely to trigger heart disease than the smoke inhaled through a filtered cigarette.

Another explanation is that a very low threshold of exposure to second-hand smoke is required for disease risk to escalate. But this idea is hard to test. Epidemiologists lament that exposure is one of the hardest factors to quantify. "There is no unit of exposure, and levels of exposure vary based on what size room people are in, the number of smokers in the room, the 
level of ventilation and so on," says Morabia.

Despite these concerns, the surgeon general's report takes a hard line on exposure, stating that there is no 'safe' level. According to Terry Pechacek, one of the authors of the report and associate director at the Office on Smoking and Health at the US Centers for Disease Control and Prevention in Atlanta, Georgia: "Exposure to second-hand smoke for even a short time can have adverse health effects - this is not subject to debate. Compounds in tobacco smoke have the ability to cause cancer in humans, it's just a probabilistic game of whether they will cause death in a certain individual."

\section{Burning opportunity}

In principle, smoking bans provide a unique opportunity to study populations before and after reductions in second-hand smoke exposure. But if research into the incidence of heart attacks is any guide, the results of such studies are often far from clear and can cause more controversy.

Glantz reported in 2004 that during a six-month smoking ban in Helena, Montana, the number of heart attacks dropped by $40 \%$ compared with the same months in other years ${ }^{7}$. The study, cited in the surgeon general's report, was criticized for the small number of cases studied and the large month-to-month variations in incidence of heart attacks.

Since the report, several studies have reported a drop in hospital admissions for heart attacks after smoking bans in the Piedmont region of Italy ( $11 \%$ drop $)^{8}$, and in small cities in Colorado $(27 \%)^{9}$ and Ohio $(39 \%)^{10}$. But not all epidemiologists are impressed. "It's quite common to see major year-to-year changes in heart attacks, sometimes as much as a $50 \%$ increase or

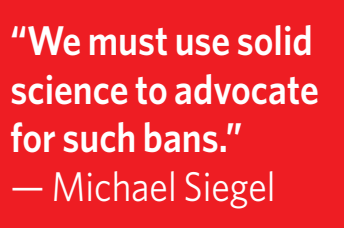

"We must use solid science to advocate for such bans." Hichael Siegel

data on groups of non-smokers and smokers in advance of a ban - and then followed them up for a few years after - would be ideal, but this would take longer and be costly.

Glantz has heard all these concerns before: "While the numbers were small in our original Helena study", he says, "the more recent ones have been in larger places." In his view, the effects have now been well documented by several studies, all of which accounted for monthly variations in heart attacks: "That is not a legitimate criticism of any of them.

\section{Lethal limits}

Certainly, public-health offidecrease," says Michael Siegel, an epidemiologist at Boston University School of Public Health. Attributing such changes to a ban is impossible, he says.

Worse, none of the studies recorded whether the changes occurred in non-smokers or in smokers, yet the effects of the ban are frequently attributed to reductions in second-hand smoke exposure. The lead author of the Ohio study agreed that a prospective study that collected cials seem convinced. Pechacek says that the general consensus in tobacco researchers is that the drop in heart attacks occurs mainly in non-smokers. Smokefree England suggests that just 30 minutes of breathing in secondhand smoke can raise your risk of having a heart attack. But can you really become ill just by sitting in a bar next to a smoker? "Saying that just a little exposure is killing people is going overboard," says Siegel, who worries

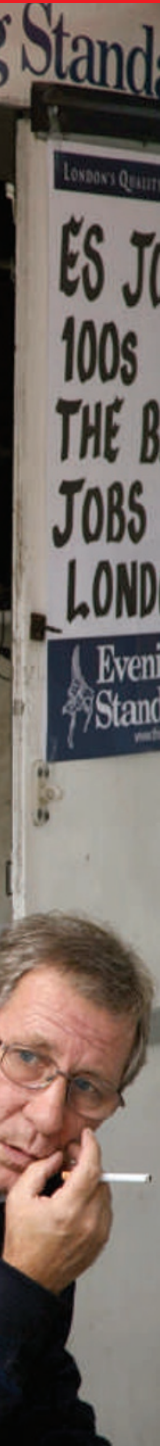

that when researchers exaggerate their findings, they lose credibility with the public. "I agree that second-hand smoke is a tremendous health hazard, but no one is going to have a heart attack from $30 \mathrm{~min}$ utes of exposure."

Siegel thinks that banning smoking in outdoor places is going too far and risks losing support for smoking bans overall. Smoking has been banned on 25 California beaches, and this week the Beverly Hills City Council approved a ban in nearly all outdoor dining areas. "We should focus efforts on the remaining areas in which workers are not protected," he says. "My biggest concern is for the waiters and bartenders who spend 40 hours each week in very smoky environments." He's also worried about the health of smoking research itself, which he sees being compromised by methodological flaws and overinterpretation of results.

And although prospective studies would be costly, Siegel argues that funding for a large prospective study of the effects of smoking bans on non-smokers is warranted. "Although I wholeheartedly support smoking bans, I still believe that we must use solid science to advocate for such bans and that a noble end - improving public health - does not justify the compromise of our scientific principles."

Other epidemiologists worry that with all the focus on second-hand smoke, the attention is being drawn away from the real issue: the dangers of smoking itself. "The key point to remember is that smokers kill themselves," says Peto. "A few are probably killing other people, but half of all smokers will be killed by their own tobacco."

Kris Novak is a freelance writer based in California. Health Services Tobacco Control Section, 2006).

. Gasparrini, A. et al. Epidemiol. Prev. 30, 348-351 (2006)

3. Menzies, D. et al. J. Am. Med. Assoc. 296, 1742-1748 (2006).

4. Goodman, P. et al. Am. J. Respir. Crit. Care Med. 175, 840-845 (2007)

5. The Health Consequences of Involuntary Exposure to Tobacco Smoke - A Report of the Surgeon General (US Department of Health and Human Services, 2006).

6. Schick, S. \& Glantz, S. Tobacco Control 14, 396-404 (2005).

7. Sargent, R. P., Shepard, R. M. \& Glantz, S. A. Br. Med. J. 328 977-980 (2004)

8. Barone-Adesi, F. et al. Eur. Heart J. 27, 2468-2472 (2006).

9. Bartecchi, C. et al. Circulation 114, 1490-1496 (2006)

10.Khuder, S. A. et al. Prev. Med. Advance online publication doi:10.1016/j.ypmed.2007.03.011(2007) 